\title{
The most important questions in cancer research and clinical oncology-Question $2-5$. Obesity-related cancers: more questions than answers
}

\author{
Ajit Venniyoor ${ }^{*}$ (D)
}

\begin{abstract}
Obesity is recognized as the second highest risk factor for cancer. The pathogenic mechanisms underlying tobaccorelated cancers are well characterized and effective programs have led to a decline in smoking and related cancers, but there is a global epidemic of obesity without a clear understanding of how obesity causes cancer. Obesity is heterogeneous, and approximately $25 \%$ of obese individuals remain healthy (metabolically healthy obese, MHO), sO which fat deposition (subcutaneous versus visceral, adipose versus ectopic) is "malignant"? What is the mechanism of carcinogenesis? Is it by metabolic dysregulation or chronic inflammation? Through which chemokines/genes/signaling pathways does adipose tissue influence carcinogenesis? Can selective inhibition of these pathways uncouple obesity from cancers? Do all obesity related cancers (ORCs) share a molecular signature? Are there common (overlapping) genetic loci that make individuals susceptible to obesity, metabolic syndrome, and cancers? Can we identify precursor lesions of ORCs and will early intervention of high risk individuals alter the natural history? It appears unlikely that the obesity epidemic will be controlled anytime soon; answers to these questions will help to reduce the adverse effect of obesity on human condition.
\end{abstract}

\section{Introduction}

There is a global obesity pandemic. Obese people get more cancers. These are two incontrovertible facts. However, attempts to clarify the mechanistic links between obesity and cancer have raised more questions than answers.

Excess body fat is a major global public health problem. In 2014, the World Health Organization classified $67 \%$ of the population of the United States, $63 \%$ of the United Kingdom, and $64 \%$ of Australia as overweight or obese [1]. The global obesity pandemic is not limited to Western countries; it also affects "poor countries" such as India. Paradoxically, while India is home to the most underweight people in the world (202 million) in 2014, it also has the fifth highest number of obese men $(9.8$ million) and third highest number of obese women (20

*Correspondence: avenniyoor@gmail.com National Oncology Center, Muscat, Oman million) [2]. The rate of increase in overweightness and obesity appears to have been highest between 1992 and 2002; although the trend in developed countries has slowed over the last decade, it continues to rise in other regions of the world [3].

Obesity accounts for approximately $5 \%$ of new cancers in adults [4], making it the second highest risk factor. Tobacco exposure is the highest risk factor; however, while the biological and natural history of tobaccorelated cancers have been elucidated and effective preventive programs have been implemented with positive results, management of obesity-related cancers (ORCs) lags far behind.

The World Cancer Research Fund (WCRF) listed 10 cancers as obesity-related [4], including post-menopausal breast, endometrial, ovarian, advanced prostate, colorectal, renal, pancreatic, liver, and gallbladder cancers, as well as esophageal adenocarcinoma. The WCRF estimated that $28 \%$ of gallbladder cancers, $35 \%$ of pancreatic 
cancers, and $35 \%$ of esophageal cancers are attributable to obesity. The International Agency for Research on Cancer (IARC) recently released an update on the link between obesity and cancer, adding another eight cancers (cancers of the gastric cardia, liver, gallbladder, pancreas, ovary, and thyroid, as well as meningioma and multiple myeloma) to their previous list of five (cancers of the colon, esophagus, kidney, breast, and uterus) as having sufficient evidence to be called risk factors [5]. Another three (prostate cancer, male breast cancer, and diffuse large B cell lymphoma) were linked with limited evidence. The IARC did not comment on association versus causation.

In the field of adiponcosis, the principal questions that need answers are as follows.

Question 1 Cancer and obesity are heterogeneous. Which molecular subtypes of cancer are related to or caused by "malignant" obesity?

\section{Background}

Obesity is heterogeneous [6]. Obesity is not always pathogenic; sometimes it is even protective. According to Denis and Obin [7] (paraphrasing Tolstoy), lean people seem to be mostly alike, whereas obese people are different, each in their own way. It seems that both obesity and cancer are heterogeneous, raising the question: what is "malignant" obesity?

Visceral adipose tissue (VAT), as indicated by central obesity, is thought to be pathogenic, whereas subcutaneous adipose tissue (SAT) is not [8]. In an interesting experiment, colonic adenoma-prone mice were divided into three groups-ad libitum fed, visceral fat removed with ad libitum feeding, and visceral fat removed with caloric restriction-and then compared. The adenoma rate was reduced by the removal of visceral fat but not by caloric restriction, indicating an independent effect of visceral fat on tumorigenesis [9].

Major studies, including the IARC report, used the body mass index (BMI) criteria for defining obesity. Although BMI is a good measure of total body fat mass, it is an inaccurate measure of clinically relevant obesity. VAT is better measured by other parameters, such as waist circumference (WC) and waist-to-hip ratio (WHR) or by computed tomography (CT) scanning [10]. An often quoted article explains how WC, not BMI, explains obesity-related health risk [11]. A recent meta-analysis suggested that central obesity measured by WC, not by WHR, is associated with modestly increased risk of both pre- and post-menopausal breast cancer, independent of general obesity [12]. More specifically, WHR adjusted for $\mathrm{BMI}$ appears to give a better measurement of clinically relevant obesity [13]. The pitfalls of using such measurements were discussed in a recent review [14]. A caveat is that our knowledge of clinically relevant obesity is from studies on metabolic syndrome (MetS) and insulin resistance; it is unclear whether ORCs have the same etiopathogenesis, and therefore it is unclear if these data are applicable. Researchers need to reach consensus on a more accurate definition and criteria for "malignant" obesity.

It is possible that excess adipose tissue is actually good for the body, indicative of adequate storage capacity for excess (and potentially lipotoxic) free fatty acid. The disease-protective effects of lower body fat have been summarized [15]. Surprisingly, the role of VAT as the pathogenic fat deposit has not yet been settled. Among the components of VAT, mesenteric fat may be more important than omental fat in metabolic dysregulation [16]. It is possible that the association between metabolic dysfunction and visceral obesity could be due to underlying processes that predispose to visceral obesity and metabolic dysfunction, rather than constituting a direct causal relationship [17].

An alternative hypothesis is that lack of adequate storage facility leads to ectopic deposition of fat in the liver and skeletal muscle, which causes insulin resistance and MetS [18]. Indeed, ectopic liver fat (ELF), which causes non-alcoholic fatty liver disease (NAFLD), predicts for and appears to be a precursor of MetS [19]. There are strong associations between obesity, MetS, and cancers [20]. Is it time to shift focus from VAT to ectopic fat as the risk factor for ORCs? (Or, in other words, does ELF cause ORC?) NAFLD is associated not only with liver cancers but also with extra-hepatic cancers [21]. Fatty liver releases "hepatokines" such as fetuin-A and FGF21 with significant roles in carcinogenesis; these roles are being investigated $[22,23]$.

It remains to be determined whether ectopic fat deposition, as measured by fat in the liver or by serum biomarkers such as alpha-ketoglutarate [24], will provide a more accurate measurement of "malignant" fat than VAT. Contradictory data exist. Conditions such as lipodystrophy, where there is absence of connective tissue fat with compensatory NAFLD and insulin resistance, do not appear to increase the risk for cancers (Dr. Abhimanyu Garg, personal communication). Additionally, African Americans are prone to obesity and ORCs but have a lower incidence of NAFLD, whereas the reverse is seen with Hispanics, who have a higher incidence of NAFLD but fewer cancers [25]. Central obesity is a stronger risk factor for cancer in Asians than in African Americans [26].

Therefore, factors that determine the distribution of fat in the deposits are relevant, and this appears to be coded 
in our genes. Evolutionarily speaking, in people from temperate climates, fat is distributed in the subcutaneous tissue where it acts as protection against cold (more SAT); if fat were distributed in the same way in people from tropical regions, it would cause overheating. In possibly the same way that the camel stores fat in its hump, people from tropical regions tend to store fat in the abdominal region (more VAT).

Clearly, the pattern of fat distribution is more important than the absolute amount of stored fat. Distribution of fat over the body is controlled by an array of "fat distribution genes." An intriguing possibility is that people inherit a pattern of fat distribution genes that makes them susceptible, simultaneously, to central obesity and cancers; therefore, both fat and cancers are related but have independent outcomes. This is in line with current ideas on the causes of obesity [27] (Fig. 1). Transcriptional profiling of gluteal and abdominal fat has identified an extensive list of differentially expressed developmental genes, including members of the homeobox (HOX) family, HOX-domain-encoding genes (for example, SHOX2 and IRX2), and T-box genes (for example, TBX15 and $T B X 5)$ [28]. These genes are known as transcriptional regulators and are involved in early embryonic development, body patterning, and cell specification. Interestingly, these genes are also implicated in the oncogenic process; that is, "fat distribution genes" are also oncogenic [29].

A genome-wide association study (GWAS) meta-analyses of traits related to waist and hip circumferences in 224,459 people identified a list of genes suspected to be involved in body fat distribution; these include familiar genes such as SMAD6, BMP2, BCL2, PPARG, and $V E G F A$, which are known to be involved in carcinogenesis [30]. Genes such as HOXC8, HOXA5, TBX15, and SFRP2 are expressed higher in VAT than SAT, and have also been implicated in carcinogenesis [31]. The exact relation needs to be further clarified; however, it does raise the possibility that both central obesity and ORCs are products of an early single event.

Approximately $10 \%-25 \%$ of obese people and a fraction of morbidly obese people do not have metabolic disturbances [32]. These "metabolically healthy, obese" (MHO) people are insulin sensitive and have normal blood pressure, a favorable lipid profile, a lower proportion of visceral fat, less liver fat, and a normal glucose metabolism, despite having an excessive amount of body fat. At the opposite end of the spectrum is a subset of normal weight people who suffer from metabolic disturbances that are characteristic of obesity (known as "metabolically obese but normal weight"). Analysis of the Framingham Heart Study of adults who were obese and glucose tolerant revealed that potentially $\mathrm{MHO}$ people have a much lower risk of obesity-associated cancer than those who are obese, glucose-intolerant, and potentially "metabolically unhealthy, obese" [33]. The implications are that obesity is not a default pro-carcinogenic state and that cancers can be uncoupled from obesity.

The brd2-deficient mouse (in which the level of $b r d 2$ gene expression is decreased; total knockout is lethal) appears to be a good model to study this possibility [34]. This mouse is obese with hyperinsulinemia but is metabolically healthy, appears to be tumor-free, and has a long life (up to 20 months). Therapeutic blocking of this gene or its pathway could be an option to be obese but healthy.

To add to the complexity, adverse sequelae of obesity can be modified by other risk factors, such as ethnicity, sex, age at which the person became obese, and especially height [35]. Compared with Caucasians at the same BMI, South Asians have approximately three times the risk and Chinese have approximately twice the risk of developing type 2 diabetes [36]. The Framingham Heart Study indicated that being overweight during adolescence may be a more significant predictor of colorectal cancer risk than being overweight during adulthood [36]. Moreover, the association of height with cancer is particularly strong

Current thinking:

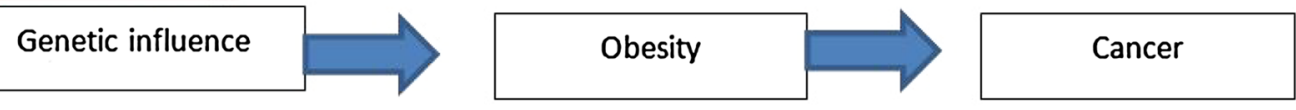

Alternate hypothesis:

Genetic influence

Obesity

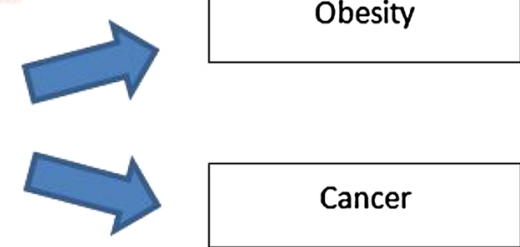

Fig. 1 Relation between obesity and cancers: an alternate view 
[35] and is one more reason why BMI is such an unreliable measurement of obesity.

Implications: There is an urgent need to better define oncogenic fat (SAT vs. VAT vs. ectopic fat) and to measure it (BMI vs. WC; CT scan vs. biopsy vs. circulating markers of NAFLD) to identify a homogenous at-risk population that can be targeted for interventions. However, such criteria should take into account ethnic differences [36]. Data from animal studies (brd2-deficient mice) and human studies (MHO people) suggest that cancer is not an invariable result of obesity and that future interventions could uncouple them.

The IARC identified several cancers that are associated with obesity [5], but it did not specify which subtype. There are many studies on the morphologic subtypes associated with obesity [37-41] (representative sample in Table 1).

However, the current emphasis is on molecular classification of cancers. Which molecular subtype(s) are linked to obesity? The new field of molecular pathological epidemiology (MPE) may provide some answers [42].

Studies linking obesity to cancer have been performed at the genetic and epigenetic levels. At the genetic level, alterations in single gene expression and gene pathways have been observed, and some molecular signatures have been generated. Alterations restricted to single genes are rarely reported. Low levels of FASN (the gene for fatty acid synthase) are seen in obesity-related colon [43] and renal cancers [44]; additionally, a relation has been observed in post-menopausal breast cancer with higher BMI [45]. FASN is associated with poor prognosis, and low levels in ORCs could explain the "obesity paradox" [39].

Although tempting, it is unlikely that single gene alterations will explain the etiology or identify environmentally derived cancers; differences are more likely to lie at least at the pathway level [46]. The data generated by various studies linking obesity to molecular subtypes are contradictory, possibly related to differing criteria of obesity. For example, many studies of colorectal cancer did not show consistency on which pathway [the $\mathrm{CpG}$

Table 1 Morphological subtypes of cancers related to obesity

\begin{tabular}{lll}
\hline No. & Site & Morphologic subtype \\
\hline 1. & Endometrium & Type l-endometroid \\
2. & Colon & Left sided \\
3. & Breast & Post-menopausal, luminal type, triple negative \\
4. & Kidney & Clear cell renal cell cancer \\
5. & Ovary & Low grade serous \\
\hline
\end{tabular}

Summarized from references [37-41] island methylator phenotype (CIMP), the chromosomal instability (CIN), or the microsomal instability (MSI) pathways] is dysregulated. Another study showed that obese patients were more likely to be microsatellite stable (MSS) with a deficient mismatch repair (dMMR) rate of $10.3 \%$, which was significantly lower than the dMMR rates of $17.1 \%, 17.4 \%$, and $21.8 \%$ in overweight, normal weight, and underweight BMI categories, respectively [47]. Overall, it appears that, at the molecular level, obesity-related colorectal cancer is CIMP-low [48] and non-MSI, with altered beta-catenin (CTNNB1) and p53. However, findings could vary depending on sex and definition of obesity (BMI vs. WHR or WC), as shown by the Malmö Diet and Cancer Study [49].

The link between obesity and prostate cancer is an example of contradictions that occur when all molecular subtypes are grouped together. A meta-analysis showed that the link between obesity and incidence of prostate cancer is weak [50]. Recent evidence suggested that obesity is specifically associated with a reduced risk of developing androgen-responsive T2E (TMPRSS2:ERG) fusion-positive tumors [51]; this fusion gene is found in $50 \%$ of prostate cancers, and this could be related to lower levels of androgen in obese men. Therefore, linkage studies should be specific not only about the type of obesity but also about the molecular subtype of cancer.

One study showed that obesity and physical inactivity were associated with a higher risk of CTNNB1-negative colorectal cancer [52]. This is consistent with findings in studies of the classical endometrioid endometrial cancer in obese women, which are usually negative [53]. A recent study analyzing The Cancer Genome Atlas (TCGA) data concluded that gene expression in endometrial cancer is related to BMI [54].

Current research using genomic profiles by techniques such as microarrays have generated molecular subtypes for most cancers (notably by TCGA). These molecular subtypes have been associated with response to treatment and survival (outcomes which are variable and strongly influenced by treatment). It is curious that less effort has gone into defining subtypes based on etiology (which is fixed). Next-generation sequencing technology enables us to observe DNA-sequence-level effects of well-known mutagens, such as ultraviolet radiation and tobacco smoke, as well as endogenous mutagenic processes, such as those involving activated DNA cytidine deaminases (APOBECs), and generate specific mutation signatures. However, so far, no obesity-associated signature has been demonstrated. GWASs conducted by multiple consortiums have generated lists of single nucleotide polymorphisms (SNPs) associated with obesity. These SNPs were used to produce genetic risk scores as a surrogate of "true" (genetic) obesity and then used to 
link obesity with cancers. The results of these Mendelian randomization studies have been usually consistent with what we know from epidemiologic studies [38, 55, 56].

Obesity is more likely to alter the epigenome than the genome [57]. Diseases including cancers can arise out of alterations in the epigenome [58, 59]. Campión et al. [60] has identified epigenetically altered genes implicated both in obesity and in cancer. Many studies have focused on the altered epigenome of obese people in blood cells and adipose tissue [61], normal breast tissue [62], breast cancer [63-65], and endometrial precursor lesions and cancer [66]. There should be more such epigenome-wide association studies (EWASs) to generate molecular signatures across other ORCs and to see if commonality can be identified across these signatures, irrespective of tissue of origin.

Multiple genomic and epigenomic studies have been done with smoking, which is the other major risk factor for cancer. GWASs have shown gene expression signatures in normal tissue that consistently differentiated never-smokers from smokers [67]. It is thought that tobacco smoke (like other environmental carcinogens) is more likely to alter the epigenome, and EWASs have identified molecular signatures specific to tobacco smoke [68-71]. Some changes are apparently precursor lesions, appearing before the onset of lung cancer [72]. It is not unreasonable to expect similar signatures for ORCs.

It would be interesting to know why some organs remain free of ORCs. For example, the brain is apparently resistant (related to the blood-brain barrier?), and finding the underlying protective mechanism could be useful. Other "protected" organs include the rectum, small intestine, urinary bladder, testis, and connective tissue. Lung cancer is another, but this could be due to the competing stronger risk factor of smoking.

Smoking is known to be associated with cancers developing at multiple sites, such as the head and neck, lung, and bladder [73, 74], but similar data are lacking in obese cancer patients. An early study based on Surveillance, Epidemiology, and End Results data suggested that multiple primary associations were compatible with the existence of common etiologic dietary elements, but this study did not specifically look at obesity [75].

Implications: Generating genome/epigenome expression profiles based on etiology rather than natural history will provide a homogenous group of ORCs, which can be further studied to clarify the mechanisms of carcinogenesis and targets for interventions.

Question 2 Through which factors/genes/signaling pathways does adipose tissue influence tumorigenesis?

How does (a specific type of) obesity cause (a specific type of) cancer? [76].
Some explanations for "adiponcosis" are site-specificfor example, esophageal adenocarcinomas due to reflux and Barret's esophagus; breast cancer due to raised estrogens generated from fatty tissue via aromatase enzyme; liver cancer due to NAFLD; and gallbladder cancer due to higher incidence of gallstones. A recent study suggested that an excess of calories suppress GUCY2C signaling (a tumor suppressor gene), resulting in intestinal tumorigenesis in obesity $[77,78]$. However, no single unifying explanation has been found to be satisfactory.

Dietary components (such as aflatoxin B) can be carcinogenic, but such cancers occur irrespective of a person's nutritional state. Unsaturated fatty acids may directly alter oncogenic pathways [79]. Direct modification of oncogenic pathways by microRNA ingested from milk is a postulated mechanism, but whether adequate amounts are absorbed is a matter of debate [80].

The two postulated mechanisms by which VAT can cause cancer are metabolic dysregulation and chronic inflammation [81]. VAT is associated with higher levels of insulin and insulin-like growth factor 1 (IGF-1) [82] and releases factors involved in metabolic dysregulation, such as adipokines (leptin and adiponectin). Major components of the inflammation pathway are cytokines such as tumor necrosis factor (TNF)-alpha, interleukin (IL)-1beta, IL-6, IL-1 receptor antagonist, soluble TNF-alpha receptor, and C-reactive protein (the "secretome") [83]. It is also unclear whether the "secretome" has a paracrine effect or endocrine. For example, does the fat around the breast (SAT) induce breast cancers, or is it an endocrine effect of cytokines from VAT? Evidence exists for both mechanisms [84-86].

The mitogenic and potentially pro-carcinogenic effects of insulin [87] have been hypothesized but unproven for decades [88]. The brd2-deficient mouse referred to earlier is obese and hyperinsulinemic but lives tumor-free [34]. In contrast, studies in "fatless mice" (A-Zif/F1) suggest that adipokines may not be as important as high levels of insulin, IGF-1, and inflammation, and activation of the phosphoinositide 3-kinase (PI3 K)/Akt pathway is central to increased cancer risk [89].

The relation between cancer and inflammation has been well summarized by Colotta et al. [90]. Up to $40 \%$ of VAT is composed of infiltrating macrophages that are thought to cause a low-grade "chronic inflammatory state," which is pro-carcinogenic. Reactive oxygen and nitrogen intermediates are obvious inflammation-generated candidates causing DNA damage [91]. While there is evidence linking inflammation and cancer [92], as seen in organ-specific inflammatory disorders such as ulcerative colitis, the evidence is weaker for systemic inflammatory disorders such as autoimmune diseases. For instance, in a large cohort of systemic lupus erythematosus patients, 
the overall risk of cancer was only marginally increased to $14 \%$, and the spectrum was different (significantly only for cancers of the vagina and liver and less so for cancers of the lung, kidney, and thyroid; cohort members had actually lower risks of cancers related to obesity, such as breast, uterus, cervix, and prostate cancers) [93]. Indeed, chronic syphilis (another inflammatory state) is traditionally thought to be protective against cancer. Colotto et al. [90] argues that it remains uncertain whether chronic inflammation per se' is sufficient for carcinogenesis. A potential candidate is galectin-3, which is secreted by macrophages infiltrating adipose tissue. Galectin-3 is an important regulator of diverse functions that are critical in cancer biology, including apoptosis, metastasis, immune surveillance, molecular trafficking, mRNA splicing, gene expression, and inflammation, and it has been recently identified as a critical factor in insulin resistance [94].

Whatever the active components of the malignant "secretome" (metabolic vs. inflammatory), it will have to act through oncogenic signaling pathways. Those implicated include the phosphatidylinositol 3-kinase/protein kinase-B/mammalian target of rapamycin (PI3 K/Akt/ mTOR), the mitogen-activated protein kinase (MAPK), the signal transducer and activator of transcription 3 (STAT3), and the NK-kB pathways. The strongest evidence exists for the PI3K/AKT/mTOR pathway, which is the proliferative pathway implicated in many cancers. For instance, many of the factors up-regulated in the obesity signal via the PI3K pathway. These include leptin, IL-6, insulin, TNF, and IGF-1 [95]. PI3K activity is increased in diet-induced obesity in mice [96], and tumor growth can be abrogated by metformin, which reduced AKT levels [97]. Tumors that are resistant to dietary restriction have constitutive activation of the PI3K pathway [98]. The evidence for involvement of PI3K pathway in obesity, inflammation and metabolic dysregulation has been summarized by Beretta et al. [99].

A couple of issues are worth speculating on. Recent studies have shown that obesity can be inherited through epigenetic changes that affected the parents (transgenerational inheritance of obesity) [100]; this raises the question of inheritance of ORCs by similar mechanisms [101]. Many cancers have familial clustering but do not have a clearly identifiable gene candidate; these are usually attributed to low-penetrance genes or SNPs. But such familial clustering could possibly be due to similar epigenetic mechanisms of transgenerational inheritance.

The second issue is, does energy imbalance act early or late in carcinogenesis? Carcinogenesis, especially when caused by environmental influences, is a multistep process, and it would be interesting to know whether obesity is the initiator or promoter of cancers.
Implications: It is essential to know which are the pathogenic elements of the secretome and through which signaling pathway(s) they act. Such information is vital from a preventive and therapeutic perspective. The possibility of transgenerational inheritance of obesity raises the possibility that a person could be susceptible to cancer just because their parents were obese; more epidemiologic studies need to be oriented towards this link.

Question 3 Are there common (overlapping) genetic loci that make individuals susceptible to obesity, metabolic syndrome, and cancers?

In other words, is there a genetic susceptibility to obesity, and are these people prone to cancers? Pigeyre et al. [102] summarized the current evidence regarding the genetic basis of obesity. Overgrowth syndromes are known to have neoplastic susceptibility [103]. Examples include WAGR (Wilms tumor), Beckwith-Weidemann syndrome (embryonal tumors), and PI3K-related syndromes (multiple tumors). This is consistent with the possibility mentioned above that a common genetic factor could predispose a person to both obesity and cancer.

However, people with polymorphisms of genes such as FTO or MC4R, which are associated with risk of obesity, have not been found to have a higher risk of colorectal [104] or endometrial cancer [105] compared with those without these polymorphisms, although a higher risk of breast cancer has been noted [106].

Epigenetic factors strongly influence susceptibility to obesity. Both intrauterine growth restriction with low birth weight, and maternal high-fat diet with high birth weight (and, to add to the complexity, low birth weight with accelerated catchup growth due to postnatal nutrition) are associated with adult obesity, insulin resistance, metabolic syndrome, NAFLD, and diabetes [107]. In sharp contrast to the large amount of data regarding metabolic perturbations, scant data exist on whether these types of obesity (assuming that different epigenetic mechanisms are at work) are associated with increased risk of cancer. Mice models suggest that the offspring of rat dams that receive a protein-restricted (low protein) diet throughout pregnancy and lactation develop mammary tumors more quickly; added nutrition simulating accelerated catchup growth increased this risk [108]. Consistent with these experimental findings, prenatal exposure to starvation increased the risk of breast cancer in women of the Dutch Famine cohort [109]; they also had higher cancer-related mortality [110]. Data also shows that the offspring of mice on a high-fat diet have a higher risk of mammary tumors. This is a cause of concern as the ill-effects of the ongoing obesity pandemic [111] could be amplified in future generations. 
Not all obese people develop cancers, and not all tissues in obese people are susceptible to ORCs. Cancer susceptibility in obese people appears to be strongly related to fat distribution (whatever the mechanism), but tissue susceptibility to ORCs is a matter of speculation. In line with the recent speculation of "bad luck" cancers, ORCs have been attributed to increased stem cell proliferation $[112,113]$ and to differential expression of insulin and IGF receptors on tissues [114].

Implications: Identification of genetically and epigenetically susceptible "at-risk" individuals is a priority for targeted early intervention. It is unclear at this point whether these tests will be in the form of genome assays or specific serum biomarkers; the ethical implications of these tests are unclear as well. The type of intervention is also not clear but encouraging data are available on drugs such as metformin [115] and on more aggressive approaches, such as bariatric surgery, in reducing the risk of cancers [116].

Question 4 Are there precursor lesions of ORCs, and will their identification help alter the natural history of such cancers?

The decline in cardiovascular mortality is due to identification of early events on the road to potentially fatal events, such as myocardial infarction and stroke (such as diabetes, hypertension, and hyperlipidemia), and aggressive treatment of the same. Unfortunately, precursor lesions (such as ductal carcinoma in situ in breast cancer, cervical intraepithelial neoplasia in cervical cancer, and polyps in colon cancer) detected during screening procedures need aggressive treatment, which is sometimes as morbid as the treatment of established cancer.

Can we detect precursor lesions for ORCs? There are tantalizing glimpses of future possibilities. Altered pattern of epigenetic changes occur even before the appearance of cancer. Biopsy of colonic mucosa of healthy women showed that methylation in distal mucosa increases with higher BMI [117]. Similarly, FASN has been shown to be overexpressed in the rectal mucosa of obese people, especially men, and has been proposed as a marker for colonic neoplasia that is present elsewhere [118]. Both "normal" endometrial glands and endometrial complex atypical hyperplasia in obese women showed low levels of p27 [119]. Other reported changes in precursor lesions include low STMN1 and high KRAS expression; KRAS mRNA expression was highly associated with high BMI [66].

However, the current data have two major limitations. One, the sensitivity, specificity, and reproducibility of these lesions have yet to be proved relevant for clinical use. Two, as shown, a universal precursor lesion that is applicable across all tissue types is yet to be demonstrated.

It is not possible to biopsy multiple organs-at-risk in obese people in the hope of finding precursor lesions. It is possible that the developing technology of "liquid biopsies" (detection of circulating tumor cells, cell free DNA, or exosomes) will prove useful in the future to screen for ORCs [120]. However, if precursor lesions are to be detected in people at high risk, we need to know the specific gene signature identifying precursor lesions of ORCs, preferably a universal signature of an ORC-related epigenome in circulating healthy or dysplastic epithelial cells. Positive liquid biopsies in such individuals would be an early warning and set the stage for interventions. Altered methylation pattern has been detected in the lymphocytes of obese people [121], but more studies are needed to identify precursor circulating epithelial cells. Several companies, such as Grail (by Illumina), are working to identify circulating tumor DNA by liquid biopsy as a method of screening for early cancer.

Implications: The ideal precursor lesion would (1) be detectable in circulating healthy or dysplastic cells on "liquid biopsies;" (2) be a molecular signature involving multiple genes (a single mutation is unlikely to explain the link, considering the heterogeneity of issues involved); (3) be universal (cutting across tissue types); (4) have a possible signature that involves alterations to the epigenome; (5) be indicative of pathways involved in metabolism and cell proliferation, possibly immunity and inflammation; and (6) contain markers for tissue of origin to localize the organ-at-risk (to avoid biopsying multiple at-risk organs).

As of now, no such biomarker exists; and from a study of the literature, there appears to be no effort to find one.

\section{Conclusions}

Obesity is believed to be a major cause of cancers. However, heterogeneity of types of obesity and types of cancers, with competing causes, has resulted in a minefield of conflicting data. The cause of obesity itself is being debated [27]. Accumulating evidence shows that the paradigm OBESITY $=$ CANCER is inaccurate.

The obesity pandemic is projected to progress, and because of this, ORCs are expected to become more common $[122,123]$. ORCs are a research priority. It is estimated that overweight and obesity accounts for $14 \%$ of all cancer deaths in men and $20 \%$ of those in women [124]. Teasing out a homogenous group of cancers that are etiologically related at the molecular level (irrespective of primary site) is vital; this can be achieved by stricter definition of obesity in molecular level. We need to improve our understanding of how epigenetic events affect a person's predisposition to obesity and how obesity affects 
the epigenome [125]. In response to the summoning of Chinese Journal of Cancer for collecting key questions in cancer research and clinical oncology [126] 4 questions are presented here. Future studies are expected to explore the following directions:

- A clearer definition of pathological obesity that can be measured easily.

- Molecular profile of ORCs based on such criteria.

- Expanded research into the causative mechanism(s).

- Research into uncoupling obesity from cancer and MetS by targeting the responsible genes.

- Repurposing of drugs currently used in MetS to test their efficacy in the prevention and treatment of ORCs.

\section{Competing interests}

The author declares that he has no competing interests.

Received: 7 November 2016 Accepted: 11 January 2017

Published online: 31 January 2017

\section{References}

1. Lennon H, Sperrin M, Badrick E, Renehan AG. The obesity paradox in cancer: a review. Curr Oncol Rep. 2016;18:56-91.

2. NCD Risk Factor Collaboration (NCD-RisC). Trends in adult body-mass index in 200 countries from 1975 to 2014: a pooled analysis of 1698 population-based measurement studies with 19.2 million participants. Lancet. 2016;387(10026):1377-96.

3. Ng M, Fleming T, Robinson M, et al. Global, regional, and national prevalence of overweight and obesity in children and adults during 1980-2013: a systematic analysis for the Global Burden of Disease Study 2013. Lancet. 2014;384(9945):766-81.

4. Arnold M, Pandeya N, Byrnes G, Renehan AG, Stevens GA, Ezzati M, et al. Global burden of cancer attributable to high body-mass index in 2012: a population-based study. Lancet Oncol. 2015;16(1):36-46.

5. Lauby-Secretan B, Scoccianti C, Loomis D, Grosse Y, Bianchini F, Straif K, International Agency for Research on Cancer Handbook Working Group. Body fatness and cancer-viewpoint of the IARC Working Group. N Engl J Med. 2016;375(8):794-8.

6. Berstein LM. Cancer and heterogeneity of obesity: a potential contribution of brown fat. Future Oncol. 2012;8(12):1537-48.

7. Denis GV, Obin MS. 'Metabolically healthy obesity': origins and implications. Mol Asp Med. 2013;34(1):59-70.

8. Lopes HF, Corrêa-Giannella ML, Consolim-Colombo FM, Egan BM. Visceral adiposity syndrome. Diabetol Metab Syndr. 2016;19(8):40.

9. Huffman DM, Augenlicht LH, Zhang $X$, et al. Abdominal obesity, independent from caloric intake, accounts for the development of intestinal tumors in $\mathrm{Apc}(1638 \mathrm{~N} /+)$ female mice. Cancer Prev Res (Phila). 2013:6(3):177-87.

10. Shuster A, Patlas M, Pinthus JH, Mourtzakis M. The clinical importance of visceral adiposity: a critical review of methods for visceral adipose tissue analysis. Br J Radiol. 2012;85(1009):1-10.

11. Janssen I, Katzmarzyk PT, Ross R. Waist circumference and not body mass index explains obesity-related health risk. Am J Clin Nutr. 2004;79(3):379-84

12. Chen GC, Chen SJ, Zhang R, Hidayat K, Qin JB, Zhang YS, Qin LQ. Central obesity and risks of pre- and postmenopausal breast cancer: a dose-response meta-analysis of prospective studies. Obes Rev. 2016. doi:10.1111/obr.12443 (Epub ahead of print).
13. de Koning L, Gerstein HC, Bosch J, et al. Anthropometric measures and glucose levels in a large multi-ethnic cohort of individuals at risk of developing type 2 diabetes. Diabetologia. 2010;53(7):1322-30.

14. Bandera EV, Fay SH, et al, World Cancer Research Fund International Continuous Update Project Panel. The use and interpretation of anthropometric measures in cancer epidemiology: a perspective from the World Cancer Research Fund international continuous update project. Int J Cancer. 2016. doi:10.1002/ijc.30248 (Epub ahead of print).

15. Karpe F, Pinnick KE. Biology of upper-body and lower-body adipose tissue: link to whole-body phenotypes. Nat Rev Endocrinol. 2015;11:90-100.

16. Tchkonia T, Lenburg M, Thomou T, et al. Identification of depot-specific human fat cell progenitors through distinct expression profiles and developmental gene patterns. Am J Physiol Endocrinol Metab. 2007;292(1):E298-307 (Epub 2006 Sep 19)

17. Tchkonia T, Thomou T, Zhu Y, et al. Mechanisms and metabolic implications of regional differences among fat depots. Cell Metab. 2013;17(5):644-56.

18. Shulman Gl. Fat in insulin resistance, dyslipidemia, and cardiometabolic disease. N Engl J Med. 2014;317:1131-41.

19. Lonardo A, Ballestri S, Marchesini G, Angulo P, Loria P. Nonalcoholic fatty liver disease: a precursor of the metabolic syndrome. Dig Liver Dis. 2015;47(3):181-90.

20. Micucci C, Valli D, Matacchione G, Catalano A. Current perspectives between metabolic syndrome and cancer. Oncotarget. 2016. doi:10.18632/oncotarget.8341.

21. Sanna C, Rosso C, Marietti M, Bugianesi E. Non-alcoholic fatty liver disease and extra-hepatic cancers. Int J Mol Sci. 2016;17(5):717. doi:10.3390/ijms17050717.

22. Jung TW, Yoo HJ, Choi KM. Implication of hepatokines in metabolic disorders and cardiovascular diseases. BBA Clin. 2016;5(5):108-13.

23. Nimptsch $\mathrm{K}$, Aleksandrova $\mathrm{K}$, Boeing $\mathrm{H}$, et al. Plasma fetuin-A concentration, genetic variation in the AHSG gene and risk of colorectal cancer. Int J Cancer. 2015;137(4):911-20.

24. Aragonès $G$, Auguet $T$, Berlanga $A$, et al. Increased circulating levels of alpha-ketoglutarate in morbidly obese women with non-alcoholic fatty liver disease. PLoS ONE. 2016;11(4):e0154601.

25. Goran MI. Ethnic-specific pathways to obesity-related disease: the Hispanic vs African-American paradox. Obesity (Silver Spring). 2008;16(12):2561-5.

26. Bandera EV, Maskarinec G, Romieu I, John EM. Racial and ethnic disparities in the impact of obesity on breast cancer risk and survival: a global perspective. Adv Nutr. 2015;6(6):803-19.

27. Ludwig DS, Friedman MI. Increasing adiposity: consequence or cause of overeating? JAMA. 2014;311(21):2167-8.

28. Schleinitz D, Böttcher Y, Blüher M, Kovacs P. The genetics of fat distribution. Diabetologia. 2014;57(7):1276-86.

29. Papaioannou VE. The T-box gene family: emerging roles in development, stem cells and cancer. Development. 2014;141:3819-33.

30. Shungin D, Winkler TW, Croteau-Chonka DC, Ferreira T, Locke AE, Mägi $R$, et al. New genetic loci link adipose and insulin biology to body fat distribution. Nature. 2015;518(7538):187-96.

31. Wang $Y$, Dang $Y$, Liu J, Ouyang $X$. The function of homeobox genes and IncRNAs in cancer. Oncol Lett. 2016:12(3):1635-41.

32. Muñoz-Garach A, Cornejo-Pareja I, Tinahones FJ. Does metabolically healthy obesity exist? Nutrients. 2016;8:320.

33. Moore LL, Chadid S, Singer MR, Kreger BE, Denis GV. Metabolic health reduces risk of obesity-related cancer in Framingham study adults. Cancer Epidemiol Biomark Prev. 2014;23(10):2057-65.

34. Wang F, Liu H, Blanton WP, Belkina A, Lebrasseur NK, Denis GV. Brd2 disruption in mice causes severe obesity without Type 2 diabetes. Biochem J. 2009;425(1):71-83.

35. Stefan N, Häring HU, Hu FB, Schulze MB. Divergent associations of height with cardiometabolic disease and cancer: epidemiology, pathophysiology, and global implications. Lancet Diabetes Endocrinol. 2016;4(5):457-67.

36. Chiu M, Austin PC, Manuel DG, Shah BR, Tu JV. Deriving ethnic-specific BM cutoff points for assessing diabetes risk. Diabetes Care. 2011;34(8):1741-8.

37. Ko EM, Walter P, Clark L, et al. The complex triad of obesity, diabetes and race in Type I and II endometrial cancers: prevalence and prognostic significance. Gynecol Oncol. 2014;133(1):28-32. 
38. Dixon SC, Nagle CM, Thrift AP, Pharoah PD, Pearce CL, et al. Adult body mass index and risk of ovarian cancer by subtype: a Mendelian randomization study. Int J Epidemiol. 2016;45(3):884-95

39. Hakimi AA, Furberg H, Zabor EC, et al. An epidemiologic and genomic investigation into the obesity paradox in renal cell carcinoma. J Natl Cancer Inst. 2013;105(24):1862-70.

40. Sueta A, Ito $H$, Islam $T$, et al. Differential impact of body mass index and its change on the risk of breast cancer by molecular subtype: a casecontrol study in Japanese women. Springerplus. 2012;1(1):39.

41. Ogino S, Chan AT, Fuchs CS, et al. Molecular pathological epidemiology of colorectal neoplasia: an emerging transdisciplinary and interdisciplinary field. Gut. 2011;60:397-411.

42. Ogino S, Nishihara R, Vander Weele TJ, et al. Review Article: the role of molecular pathological epidemiology in the study of neoplastic and non-neoplastic diseases in the era of precision medicine. Epidemiology. 2016;27(4):602-11.

43. Ogino S, Nosho K, Meyerhardt JA, et al. A cohort study of fatty acid synthase expression and patient survival in colon cancer. J Clin Oncol. 2008;26(35):5713-20.

44. Albiges $L$, Hakimi AA, Xie W, et al. Body mass index and metastatic renal cell carcinoma: clinical and biological correlations. J Clin Oncol. 2016:34(30):3655-63.

45. Porta R, Blancafort A, Casòliva G, et al. Fatty acid synthase expression is strongly related to menopause in early-stage breast cancer patients. Menopause. 2014;21(2):188-91.

46. Chen J, Wang Y, Shen B, Zhang D. Molecular signature of cancer at gene level or pathway level? Case studies of colorectal cancer and prostate cancer microarray data. Comput Math Methods Med. 2013:2013:909525.

47. Sinicrope FA, Foster NR, Yothers G, et al, Adjuvant Colon Cancer Endpoints (ACCENT) Group. Body mass index at diagnosis and survival among colon cancer patients enrolled in clinical trials of adjuvant chemotherapy. Cancer. 2013;119(8):1528-36.

48. Morikawa T, Kuchiba A, Yamauchi M, et al. Association of CTNNB1 (betacatenin) alterations, body mass index, and physical activity with survival in patients with colorectal cancer. JAMA. 2011;305(16):1685-94.

49. Brändstedt J, Wangefjord S, Borgquist S, et al. Influence of anthropometric factors on tumour biological characteristics of colorectal cancer in men and women: a cohort study. J Transl Med. 2013;21(11):293-306.

50. GolabekT, Bukowczan J, Chłosta P, et al. Obesity and prostate cance incidence and mortality: a systematic review of prospective cohort studies. Urol Int. 2014;92(1):7-14.

51. Egbers L, Luedeke M, Rinckleb A, et al. Obesity and prostate cancer risk according to tumor TMPRSS2:ERG gene fusion status. Am J Epidemiol. 2015;181(9):706-13.

52. Morikawa T, Kuchiba A, Lochhead P, et al. Prospective analysis of body mass index, physical activity, and colorectal cancer risk associated with $\beta$-catenin (CTNNB1) status. Cancer Res. 2013;73(5):1600-10.

53. Liu Y, Broaddus RR, Zhang W. Identifying aggressive forms of endometrial cancer: new insights into molecular typing. Exp Rev Anticancer Ther. 2015;15(1):1-3.

54. Roque DR, Makowski L, Chen TH, Rashid N, Hayes DN, Bae-Jump V. Association between differential gene expression and body mass index among endometrial cancers from The Cancer Genome Atlas Project. Gynecol Oncol. 2016;142(2):317-22.

55. Thrift AP, Shaheen NJ, Gammon MD, et al. Obesity and risk of esophageal adenocarcinoma and Barrett's esophagus: a Mendelian randomization study. J Natl Cancer Inst. 2014;106(11):dju252.

56. Prescott J, Setiawan VW, Wentzensen N, et al. Body mass index genetic risk Score and endometrial cancer risk. PLOS ONE. 2015:10(11):e0143256.

57. van Dijk SJ, Molloy PL, Varinli H, Morrison JL, Muhlhausler BS. Members of EpiSCOPE. Epigenetics and human obesity. Int J Obes (Lond). 2015;39(1):85-97.

58. Rakyan VK, Down TA, Balding DJ, Beck S. Epigenome-wide association studies for common human diseases. Nat Rev Genet. 2011;12(8):529-41.

59. Feinberg AP, Ohlsson R, Henikoff S. The epigenetic progenitor origin of human cancer. Nat Rev Genet. 2006;7(1):21-33.

60. Campión J, Milagro Fl, Martínez JA. Individuality and epigenetics in obesity. Obes Rev. 2009;10(4):383-92.
61. Dick KJ, Nelson CP, Tsaprouni L, et al. DNA methylation and body-mass index: a genome-wide analysis. Lancet. 2014;383(9933):1990-8.

62. Hair BY, Xu Z, Kirk EL, et al. Body mass index associated with genome-wide methylation in breast tissue. Breast Cancer Res Treat. 2015;151(2):453-63.

63. Hair BY, Troester MA, Edmiston SN, et al. Body mass index is associated with gene methylation in estrogen receptor-positive breast tumors. Cancer Epidemiol Biomarkers Prev. 2015;24(3):580-6.

64. Tao MH, Marian C, Nie J, et al. Body mass and DNA promoter methylation in breast tumors in the Western New York Exposures and Breast Cancer Study. Am J Clin Nutr. 2011;94(3):831-8.

65. McCullough LE, Chen J, White AJ, et al. Gene-specific promoter methylation status in hormone-receptor-positive breast cancer associates with postmenopausal body size and recreational physical activity. Int J Cancer Clin Res. 2015;2(1):13.

66. Berg A, Hoivik EA, Mjøs S, et al. Molecular profiling of endometrial carcinoma precursor, primary and metastatic lesions suggests different targets for treatment in obese compared to non-obese patients. Oncotarget. 2015;6(2):1327-39

67. Bossé Y, Postma DS, Sin DD, et al. Molecular signature of smoking in human lung tissues. Cancer Res. 2012;72(15):3753-63.

68. Lee KW, Pausova Z. Cigarette smoking and DNA methylation. Front Genet. 2013;4:132.

69. Besingi W, Johansson A. Smoke-related DNA methylation changes in the etiology of human disease. Hum Mol Genet. 2014;23(9):2290-7.

70. Breitling LP, Yang R, Korn B, Burwinkel B, Brenner H. Tobacco-smokingrelated differential DNA methylation: $27 \mathrm{~K}$ discovery and replication. Am J Hum Genet. 2011;88(4):450-7.

71. Gao X, Jia M, Zhang Y, Breitling LP, Brenner H. DNA methylation changes of whole blood cells in response to active smoking exposure in adults: a systematic review of DNA methylation studies. Clin Epigenetics. 2015;16(7):113.

72. Fasanelli F, Baglietto L, Ponzi E, et al. Hypomethylation of smokingrelated genes is associated with future lung cancer in four prospective cohorts. Nat Commun. 2015;15(6):10192.

73. Engeland A, Bjorge T, Haldorsen T, Tretli S. Use of multiple primary cancers to indicate associations between smoking and cancer incidence: an analysis of 500,000 cancer cases diagnosed in Norway during 1953-1993. Int J Cancer. 1997;70:401-7.

74. Utada M, Ohno Y, Hori M, Soda M. Incidence of multiple primary cancers and interval between first and second primary cancers. Cancer Sci. 2014;105(7):890-6.

75. Schatzkin A, Baranovsky A, Kessler LG. Diet and cancer: evidence from associations of multiple primary cancers in the SEER program. Cancer. 1988:62(7):1451-7.

76. Khandekar MJ, Cohen P, Spiegelman BM. Molecular mechanisms of cancer development in obesity. Nat Rev Cancer. 2011;11:886-95.

77. Lin JE, Colon-Gonzalez F, Blomain E, et al. Obesity-induced colorectal cancer is driven by caloric silencing of the guanylin-GUCY2C paracrine signaling axis. Cancer Res. 2016;76(2):339-46.

78. Blomain ES, Merlino DJ, Pattison AM, Snook AE, Waldman SA. Guanylyl cyclase $C$ hormone axis at the intersection of obesity and colorectal cancer. Mol Pharmacol. 2016;90(3):199-204.

79. Couplan E, Le Cann M, Le Foll C, Corporeau C, Blondel M, Delarue J. Polyunsaturated fatty acids inhibit PI3 K activity in a yeast-based model system. Biotechnol J. 2009;4(8):1190-7.

80. Melnik BC. Milk: an epigenetic amplifier of FTO-mediated transcription? Implications for Western diseases. J Transl Med. 2015;21(13):385.

81. Berger NA. Obesity and cancer pathogenesis. Ann NY Acad Sci. 2014;1311:57-76.

82. Pollak M. The insulin and insulin-like growth factor receptor family in neoplasia: an update. Nat Rev Cancer. 2012;12(3):159-69.

83. Cabia B, Andrade S, Carreira MC, Casanueva FF, Crujeiras AB. A role for novel adipose tissue-secreted factors in obesity-related carcinogenesis. Obes Rev. 2016;17(4):361-76.

84. Santander AM, Lopez-Ocejo O, Casas O, et al. Paracrine interactions between adipocytes and tumor cells recruit and modify macrophages to the mammary tumor microenvironment: the role of obesity and inflammation in breast adipose tissue. Cancers (Basel). 2015;7(1):143-78.

85. Nieman KM, Romero IL, Van Houten B, Lengyel E. Adipose tissue and adipocytes support tumorigenesis and metastasis. Biochim Biophys Acta. 2013;1831(10):1533-41. 
86. Crujeiras AB, Cabia B, Carreira MC, et al. Secreted factors derived from obese visceral adipose tissue regulate the expression of breast malignant transformation genes. Int J Obes (Lond). 2016;40(3):514-23.

87. Poloz Y, Stambolic V. Obesity and cancer, a case for insulin signaling. Cell Death Dis. 2015;31(6):e2037.

88. Donohoe CL, Doyle SL, Reynolds JV. Visceral adiposity, insulin resistance and cancer risk. Diabetol Metab Syndr. 2011;3:12.

89. Hursting SD, Nunez NP, Varticovski L, Vinson C. The obesity-cancer link: lessons learned from the fatless mice. Cancer Res. 2007;67(6):2391-3.

90. Colotta F, Allavena P, Sica A, Garlanda C, Mantovani A. Cancer-related inflammation, the seventh hallmark of cancer: links to genetic instability. Carcinogenesis. 2009;30(7):1073-81.

91. Cerdá C, Sánchez C, Climent B, et al. Oxidative stress and DNA damage in obesity-related tumorigenesis. Adv Exp Med Biol. 2014;824:5-17.

92. Di Donato JA, Mercurio F, Karin M. NF-KB and the link between inflammation and cancer. Immunol Rev. 2012;246(1):379-400.

93. Parikh-Patel A, White RH, Allen M, Cress R. Cancer risk in a cohort of patients with systemic lupus erythematosus (SLE) in California. Cancer Causes Control. 2008;19(8):887-94

94. Li P, Liu S, Lu M, et al. Hematopoietic-derived galectin-3 causes cellular and systemic insulin resistance. Cell. 2016;167(4):973-84.

95. Chen J. Multiple signal pathways in obesity-associated cancer. Obes Rev. 2011;12(12):1063-70.

96. Moore T, Beltran L, Carbajal S, et al. Dietary energy balance modulates signaling through the Akt/mammalian target of rapamycin pathways in multiple epithelial tissues. Cancer Prev Res (Phila). 2008;1(1):65-76.

97. Algire C, Amrein L, Zakikhani M, Panasci L, Pollak M. Metformin blocks the stimulative effect of a high-energy diet on colon carcinoma growth in vivo and is associated with reduced expression of fatty acid synthase. Endocr Relat Cancer. 2010;17(2):351-60.

98. Kalaany NY, Sabatini DM. Tumours with PI3 K activation are resistant to dietary restriction. Nature. 2009;458(7239):725-31.

99. Beretta M, Bauer M, Hirsch E. PI3 K signaling in the pathogenesis of obesity: the cause and the cure. Adv Biol Regul. 2015;58:1-15.

100. Wadhwa PD, Buss C, Entringer S, Swanson JM. Developmental origins of health and disease: brief history of the approach and current focus of epigenetic mechanisms. Semin Reprod Med. 2009;27(5):358-68.

101. Lillycrop KA, Burdge GC. The effect of nutrition during early life on the epigenetic regulation of transcription and implications of human diseases. J Nutrigenetics Nutrigenomics. 2011:4(5):248-60.

102. Pigeyre M, Yazdi FT, Kaur Y, Meyre D. Recent progress in genetics, epigenetics and metagenomics unveils the pathophysiology of human obesity. Clin Sci (Lond). 2016;130(12):943-86.

103. Edmondson AC, Kalish JM. Overgrowth syndromes. J Pediatr Genet. 2015;4(3):136-43.

104. Yang B, Thrift AP, Figueiredo JC, et al. Common variants in the obesityassociated genes FTO and MC4R are not associated with risk of colorectal cancer. Cancer Epidemiol. 2016:44:1-4.

105. Lurie G, Gaudet MM, Spurdle AB, et al. The obesity-associated polymorphisms FTO rs9939609 and MC4R rs17782313 and endometrial cancer risk in non-Hispanic white women. PLOS ONE. 2011:6(2):e16756.

106. da Cunha PA, de Carlos Back LK, et al. Interaction between obesityrelated genes, FTO and MC4R, associated to an increase of breast cancer risk. Mol Biol Rep. 2013;40(12):6657-64.

107. Brenseke B, Prater MR, Bahamonde J, Gutierrez C. Current thoughts on maternal nutrition and fetal programming of the metabolic syndrome. J Preg. 2013:2013:368461. doi:10.1155/2013/368461
108. Fernandez-Twinn DS, Ekizoglou S, Martin-Gronert MS, et al. Poor early growth and excessive adult calorie intake independently and additively affect mitogenic signaling and increase mammary tumor susceptibility. Carcinogenesis. 2010;31(10):1873-81.

109. Elias SG, Peeters PH, Grobbee DE, van Noord PA. The 1944-1945 Dutch famine and subsequent overall cancer incidence. Cancer Epidemiol Biomark Prev. 2005;14(8):1981-5.

110. van Abeelen AF, Veenendaal MV, Painter RC, et al. Survival effects of prenatal famine exposure. Am J Clin Nutr. 2012:95(1):179-83.

111. Montales MT, Melnyk SB, Simmen FA, Simmen RC. Maternal metabolic perturbations elicited by high-fat diet promote Wnt-1-induced mammary tumor risk in adult female offspring via long-term effects on mammary and systemic phenotypes. Carcinogenesis. 2014;35(9):2102-12

112. Tomasetti C, Vogelstein B. Cancer etiology. Variation in cancer risk among tissues can be explained by the number of stem cell divisions. Science. 2015;347(6217):78-81.

113. Luzzatto L, Pandolfi PP. Causality and chance in the development of cancer. N Engl J Med. 2015;373(16):1579.

114. Speakman JR, Goran MI. Tissue-specificity and ethnic diversity in obesity-related risk of cancer may be explained by variability in insulin response and insulin signaling pathways. Obesity (Silver Spring). 2010;18(6):1071-8.

115. Kasznicki J, Sliwinska A, Drzewoski J. Metformin in cancer prevention and therapy. Ann Transl Med. 2014;2(6):57-62.

116. Adams TD, Mehta TS, Davidson LE, Hunt SC. All-cause and causespecific mortality associated with bariatric surgery: a review. Curr Atheroscler Rep. 2015;17(12):74.

117. Noreen F, Roosli M, Gaj P, Pietrzak J, Weis S, Urfer P, et al. Modulation of age- and cancer-associated DNA methylation change in the healthy colon by aspirin and lifestyle. J Natl Cancer Inst. 2014;106:dju161.

118. Cruz MD, Wali RK, Bianchi LK, et al. Colonic mucosal fatty acid synthase as an early biomarker for colorectal neoplasia: modulation by obesity and gender. Cancer Epidemiol Biomark Prev. 2014;23(11):2413-21.

119. McCampbell AS, Mittelstadt ML, Dere R, et al. Loss of p27 associated with risk for endometrial carcinoma arising in the setting of obesity. Curr Mol Med. 2016;16(3):252-65.

120. Alix-Panabières C, Pantel K. Clinical applications of circulating tumor cells and circulating tumor DNA as liquid biopsy. Cancer Discov. 2016;6(5):479-91.

121. Jacobsen MJ, Mentzel CM, Olesen AS, Huby T, Jørgensen CB, Barrès R, Fredholm M, Simar D. Altered methylation profile of lymphocytes is concordant with perturbation of lipids metabolism and inflammatory response in obesity. J Diabetes Res. 2016:2016:8539057.

122. Whiteman DC, Wilson LF. The fractions of cancer attributable to modifiable factors: a global review. Cancer Epidemiol. 2016;44:203-21.

123. Arnold M, Leitzmann M, Freisling $H$, Bray F, Romieu I, Renehan A, Soerjomataram I. Obesity and cancer: an update of the global impact. Cancer Epidemiol. 2016;41:8-15.

124. Calle EE, Rodriguez C, Walker-Thurmond K, Thun MJ. Overweight, obesity and mortality in a prospectively studied cohort of U.S. adults. N Engl J Med. 2003;348:1625-38.

125. Franks PW, Ling C. Epigenetics and obesity: the devil is in the details. BMC Med. 2010;8:88.

126. Qian CN, Zhang W, Xu RH. Defeating cancer: the 150 most important questions in cancer research and clinical oncology. Chin J Cancer. 2016:35:104. 